\section{Clinical Tests of Thyroid Function}

By John A. Thomson. Pp. 108, illustrated. London: Granada Publishing, 1974. £4.50.

Anybody familiar with the enormous range of thyroid disorders, both in adult life and in childhood, will welcome this publication which does much to simplify the apparent confusion and proliferation of tests of thyroid function. This is a book obviously compiled by a physician who has dealt extensively and practically with all the problems it contains. It has a nice chapter on the physiological data, of the physical transport and the mode of action of thyroid hormone. The tests in routine use are clearly and concisely propounded, followed by an account of those tests more recently elaborated. Special indications in unusual circumstances such as pregnancy and the newborn are clearly presented and their rationale discussed. A rather nice chapter on clinical examples is written in such a way that is both easy and interesting to read.

It is a book of clear, sound, practical guidance for general physicians and thyroid specialists alike.

\section{A Colour Atlas of ENT Diagnosis}

By T. R. Bull. Pp. 240, illustrated. London: Wolfe Publishing, 1974. £4.50.

In the early decades of this century medical books were printed with elaborate painted illustrations. Somehow they never quite achieved their purpose and the experienced surgeon inevitably felt that things were never exactly as shown. In modern times, with the emphasis on early diagnosis, the older illustrations, usually showing gross lesions, are little more than curiosities.

It is with pleasure, therefore, that we welcome this new book to ENT literature. Excellent colour photography and the care and selection of suitable cases reproduces exactly the lesions we see. Mr Bull has shown them at the stage that we are usually asked to recognize them, and the concise text is both easy to read and covers the field quite adequately. Particularly important are the pictures of the tympanic membrane and the care $\mathrm{Mr}$ Bull has taken in showing the various different types of normal drumhead. The decision to show pictures of the equipment in the audiology section is useful and contributes to the description of the tests.

This book can be recommended to medical students, general practitioners, and casualty officers as a valuable companion to the textbooks on the subject. 